\title{
Anti-diabetic Drugs Utilization in Type 2 Diabetic Patients in AL-Nasiriya Governorate / Iraq
}

\author{
Basim Audib Motar \\ Department of Internal Medicine, Thi-Qar University, Thi-Qar, Iraq \\ Email address: \\ dr.basim_moter@yahoo.com \\ To cite this article: \\ Basim Audib Motar. Anti-diabetic Drugs Utilization in Type 2 Diabetic Patients in AL-Nasiriya Governorate / Iraq. American Journal of \\ Internal Medicine. Vol. 5, No. 6, 2017, pp. 117-124. doi: 10.11648/j.ajim.20170506.12
}

Received: August 28, 2017; Accepted: October 9, 2017; Published: November 10, 2017

\begin{abstract}
To study the utilization pattern of anti-diabetic drugs in type 2 diabetic patients and to evaluate the association of diabetes with demographic details and it's metabolic control. The study was carried out on 100 type 2 diabetic patients who visited AL- Nasiriya center for diabetes and endocrinology. Demographic details and complete prescriptions drugs, FBS (fasting blood sugar), HbAlc and BMI (body mass index) were recorded. A total of 100 type 2 diabetic patients, 27(27\%) were males and $73(73 \%)$ were females. The greatest number of patients, $43 \%$, were in the age group of 51-60 years. Obesity (BMI $\geq$ 30 ) were found in $51 \%$ of patients especially females $45(61.3 \%)$. Poor glycemic control (HbAlc $\geq 9)$ were found in $65 \%$ of the patients. Oral anti-diabetic drugs were prescribed in 53\%, 16(60\%) were males and $37(50.6 \%)$ were females. Biguanide (metformin) alone, 22\%, was the most common anti-diabetic drugs prescribed. Biguanides (metformin) and sulfonylurea combination, $19 \%$, was the commonest anti-diabetic drugs combination. Insulin preparations alone were used in $23 \%$ of the patients and Novomix was the commonest type (10\%). We concluded that oral anti-diabetic drugs were the most common prescribing drugs. Metformin was the commonest prescribing anti-diabetic drugs. Metformin and sulfonylurea being the most frequent combination prescribed. There were increasing in the use on insulin preparations in the treatment of type 2 diabetic patients. In achieving optimal glycemic control, the efficacy of anti-diabetic drugs was only $10 \%$, planning of more intensification anti-diabetic treatment is necessary.
\end{abstract}

Keywords: Antidiabetic Drugs, Type 2 Diabetes Mellitus, Glycemic Control

\section{Introduction}

Type 2 diabetes mellitus is a disease marked by high levels of blood glucose due to the action of insulin and insufficient insulin production. Type 2 diabetes accounts for approximately $90 \%$ to $95 \%$ of all diagnosed cases of diabetes [1]. Type 2 diabetes mellitus is one of the most common chronic conditions in the elderly [2]. Diabetes mellitus (DM) is one of the oldest diseases known to man, which was the first reported in Egyptian literature about 3000 years ago [3]. The Greek Physician Aretaeus (30-90 CE) first gave the name diabetes. Avicenna, is the famous Arabian physician who first described the complication and progression of the disease [4].

Diabetes mellitus type 2 is a chronic disease characterized by coexisting insulin deficiency and insulin resistance, with the resultant hyperglycemia leading to micro and macro vascular complications [5, 6]. Complications include altered metabolism of lipids, carbohydrates, protein and an increased risk of vascular disease complication $[7,8]$.

The diagnosis of DM is based on the American Diabetes Association (ADA) guidelines or World Health Organization (WHO) national diabetic group criteria, which is for a single glucose reading with symptoms (polyuria, polydipsia, polyphagia and weight loss), or raised values on two occasions in asymptomatic patients $[9,10]$.

Complications due to hyperglycemia in diabetes mellitus can be prevented by using rational use of oral antidiabetic drugs (OADs) and insulin [11].

Rational use of the drugs is a complex issue with a goal that is difficult to achieve, defined as follows: That patients receive medications appropriate to their clinical needs, in doses that meet their own individual requirements for an adequate period of time, and at the lowest cost to them and their community [12]. Rational use of the drugs in population can be effectively studied with drug utilization reviews. The World Health Organization (WHO) defines "drug utilization" 
as the marketing, distribution, prescription and use of the drugs in a society considering its consequences, either medical, social, and economic [13].

Various classes of anti-diabetic drugs including oral hypoglycemic agents (OHA) and insulin are currently used in the treatment of diabetes, which acts by different mechanisms to reduce the blood glucose levels to maintain optimal glycemic control $[14,15]$.

The United Kingdom Prospective Diabetes Study showed intensive blood-glucose control by either sulfonylureas or insulin substantially decreased the risk of microvascular complications [16].

Because of the progressive nature of the disease, an evolving treatment strategy is therefore necessary to maintain both fasting and postprandial glycemic control. ADA and European Association for the Study of Diabetes (ESAD) Consensus recommended a target of $\mathrm{HbA1c}<7 \%$ for good glucose control in clinical practice [17]. Selection of oral antidiabetic drugs as first line drug or combined therapy should be based on both the pharmacological properties of the compounds like efficacy, safety profile and also on the clinical characteristics of the patient like stage of disease, body weight, body mass index (BMI) [18]. More than 50\% of people with diabetes have poor glycemic control and a large percentage have diabetic vascular complications [19].

United Kingdom Prospective Diabetes Study (UKPDS) advocates for increasing requirement of multiple therapies in patients with type 2 diabetes to achieve blood glucose target control [20]. Although the benefits of tight control of blood glucose have been well recognized and supported with evidences of several studies, the management of diabetes is complex, and considered to be not quite successful in a realworld setting [21, 22].

A wide range of oral antidiabetic drugs such as sulfonylurea and biguanides have been used for since the last 50 years for the treatment of diabetes. The last decade and a half has seen the introduction of a number of oral antidiabetic drugs like Alpha-glucosidase inhibitors, thiazolidinediones, meglitinides and the most recently introduced dipeptidyl peptidase-4 (DPP4) inhibitors [23]. A study on drug utilization can provide valuable information to the physicians, researchers to determine the drug use pattern [24].

\section{Method}

\subsection{Patients}

The study was a retrospective study carried out in 100 established type 2 diabetic patients, age range from $40-80$ years who visited the Diabetic and Endocrinology center in
AL-Nasiriya city during the time period of January 2015 to March 2015. Type 2 diabetes mellitus patients, irrespective of age and sex, who were prescribed one antidiabetic agents or more, were included in the present study.

Diagnosed type 2 diabetic patients who do not receive pharmacological therapy, prediabetic status, diabetic complications and serious medical conditions requiring subsequent hospital admissions were excluded from the study.

\subsection{Material}

Demographic data like age, sex, body weight, height, family history, detailed medical history, medications for diabetes mellitus, duration of treatment, concomitant medications for co-morbid disease, questions regarding lifestyle, dietary pattern, and exercise programme were recorded in this study. In addition, fasting, postprandial blood glucose and HbAlc was measured. Fasting blood sugar and postprandial blood glucose were measured by enzymatic method. HbA1c was measured by high performance liquid chromatography. Body mass index (BMI) was calculated as weight in kilograms divided by height in meter squared.

\subsection{Statistical Analysis}

The collected data were analyzed for their appropriateness and suitability and interpretation was made. Statistical analysis was done by SPSS (Version 11.2) software. Statistical methods used were simple frequencies and percentages.

\section{Result}

A total of 100 type 2 diabetic patients, 27 (27\%) were male and $73(73 \%)$ were female, were collected in the study during the period of 3 months as show in figure 1 .

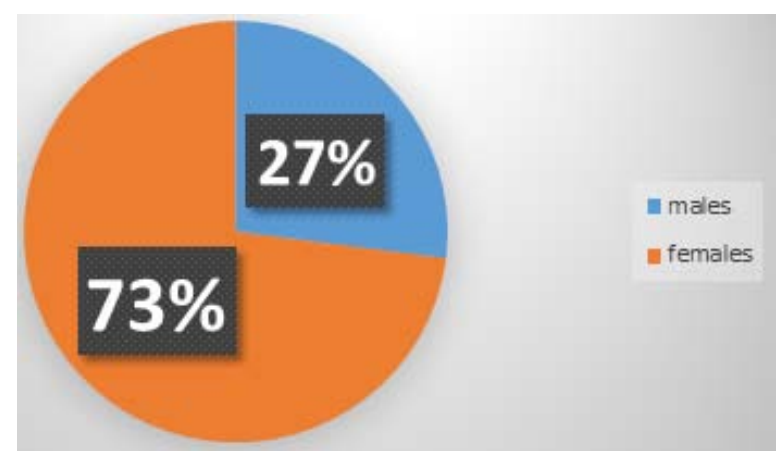

Figure 1. Distribution of the Patients in This Study.

Table 1 show the demographic characteristics of the population studied.

Table 1. Demographic Characters of the Patients in the Study.

\begin{tabular}{|c|c|c|c|}
\hline Demographic characters & No. of patients & & Total \\
\hline \multicolumn{4}{|l|}{ Sex } \\
\hline Male & $27 \%$ & & 1000 \\
\hline female & $73 \%$ & & $100 \%$ \\
\hline Age & Male & female & \\
\hline $40-50$ years & $8(29.6 \%)$ & $22(30.3 \%)$ & $30 \%$ \\
\hline
\end{tabular}




\begin{tabular}{|c|c|c|c|}
\hline Demographic characters & No. of pati & & Total \\
\hline $51-60$ years & $13(48 \%)$ & $30(41 \%)$ & $43 \%$ \\
\hline $61-70$ years & $3(11.2)$ & $18(24.7 \%)$ & $21 \%$ \\
\hline $71-80$ years \& more & $3(11.2)$ & $3(4 \%)$ & $6 \%$ \\
\hline Body mass index & Male & female & \\
\hline Normal (18.5 -24.9) & $10(37 \%)$ & $11(15.3 \%)$ & $21 \%$ \\
\hline Overweight( 25 or more) & $11(40 \%)$ & $17(23.4 \%)$ & $28 \%$ \\
\hline $\mathrm{HbA1c}$ & Male & female & \\
\hline Good (less than 7) & $2(7.5 \%)$ & $8(11 \%)$ & $10 \%$ \\
\hline Inadequate (7-8.9) & $12(44.5 \%)$ & $13(18 \%)$ & $25 \%$ \\
\hline Poor ( 9 and above ) & $13(48 \%)$ & $52(71 \%)$ & $65 \%$ \\
\hline Type of treatment & Male & female & \\
\hline Oral & $16(60 \%)$ & $37(50.6 \%)$ & $53 \%$ \\
\hline Injectable (insulin) & $5(18.5 \%)$ & $18(24.7 \%)$ & $23 \%$ \\
\hline Combined (oral + insulin) & $6(21.5 \%)$ & $18(24.7 \%)$ & $24 \%$ \\
\hline
\end{tabular}

The table show the majority of the patients were found in the age group of 51-60 years, males were $13(48 \%)$ and females were $30(41 \%)$ as show in figure 2 .

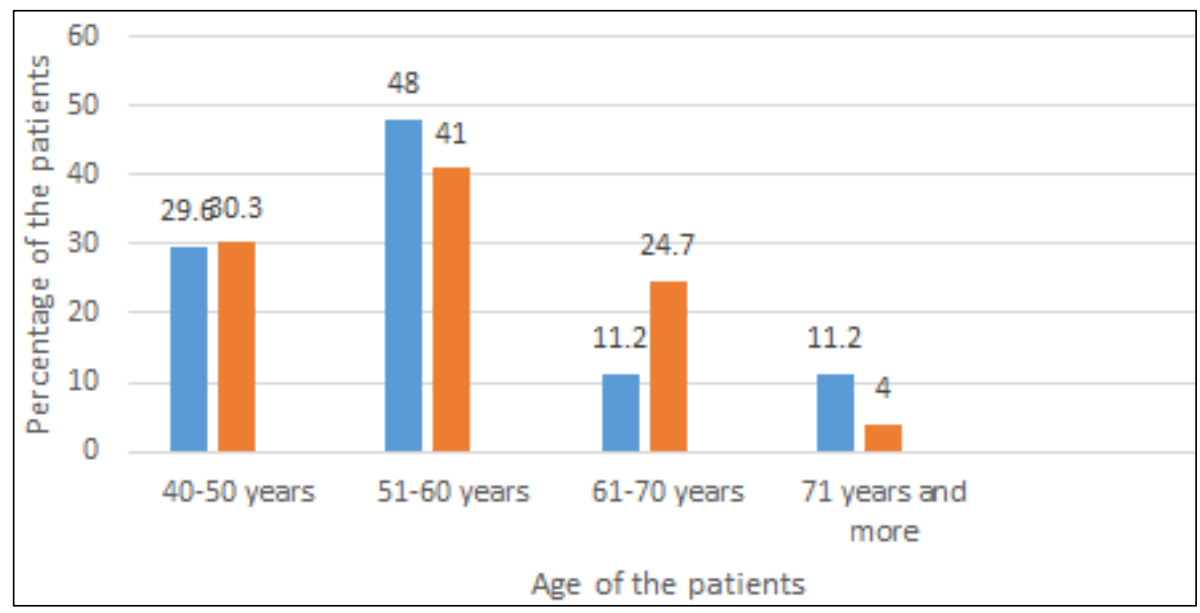

Figure 2. Age Distribution of the Patients in This Study.

Obesity (BMI $\geq 30$ ) was found in the majority of the patients especially females, $45(61.3 \%)$ females and $6(23 \%)$ was males, as shown in figure 3 .

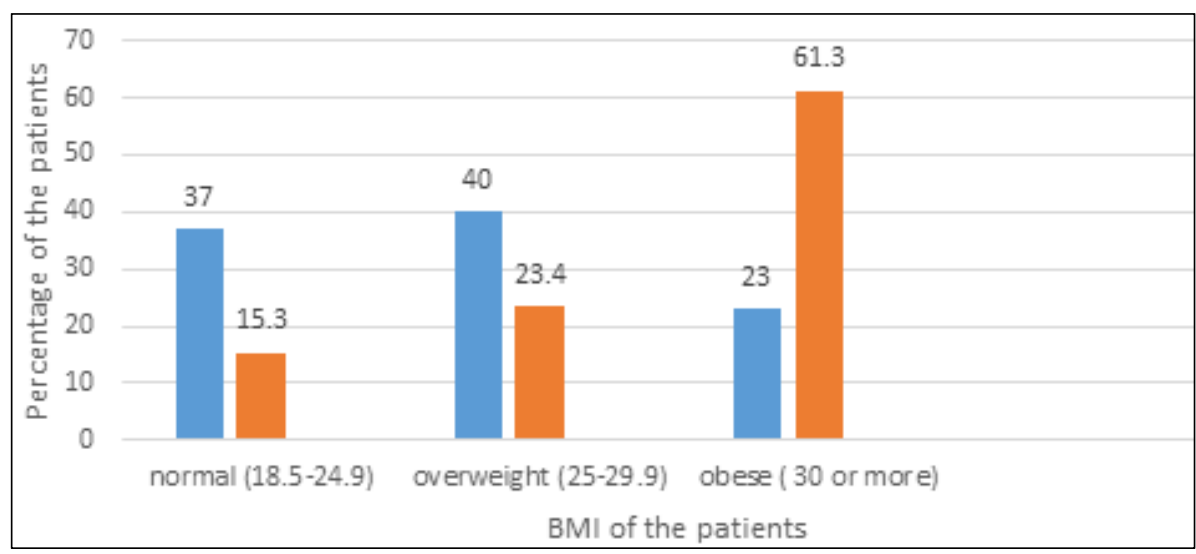

Figure 3. Body Mass Index Distribution in Relation to Sex.

The majority of the patients studied, $13(48 \%)$ males and $52(71 \%)$ females were with poor glycemic control (HbAlc $\geq 9)$ as shown in figure 4. 


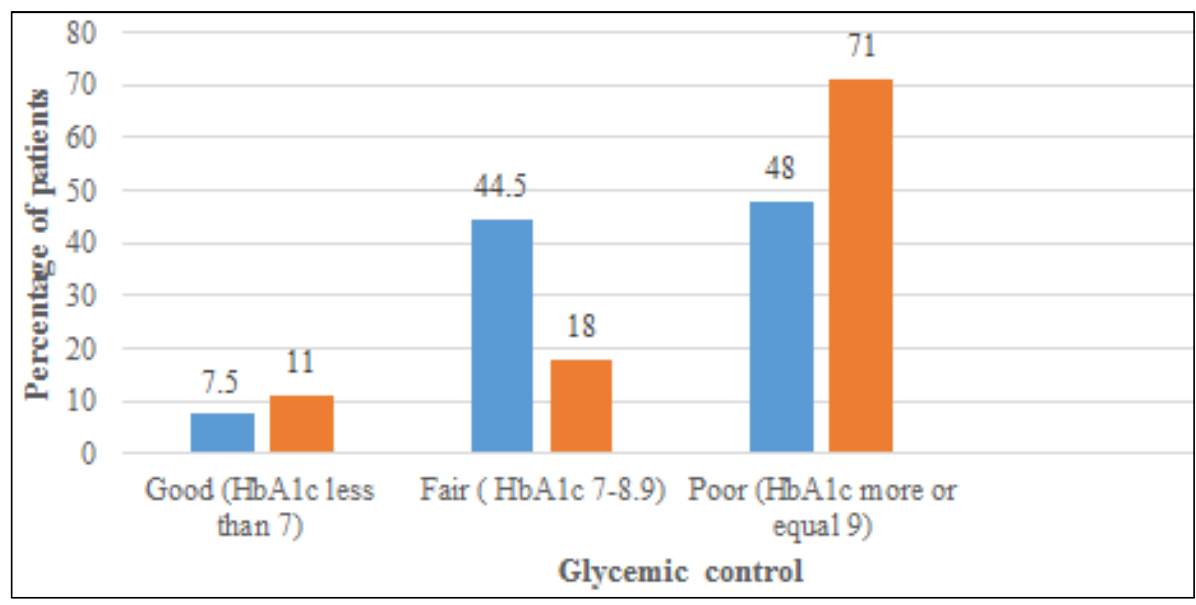

Figure 4. Distribution of Patients According to HbAlc in Relation to Sex.

Out of total 100 patients included in this study, the oral anti-diabetic drugs were the most commonly prescribed drugs, $16(60 \%)$ were male and $37(50.6 \%)$ were female. $5(18.5 \%)$ male and $18(24.7 \%)$ female were on insulin alone while $6(21.5 \%)$ male and $18(24.7 \%)$ female were on combined oral and insulin therapy, as shown in figure 5.

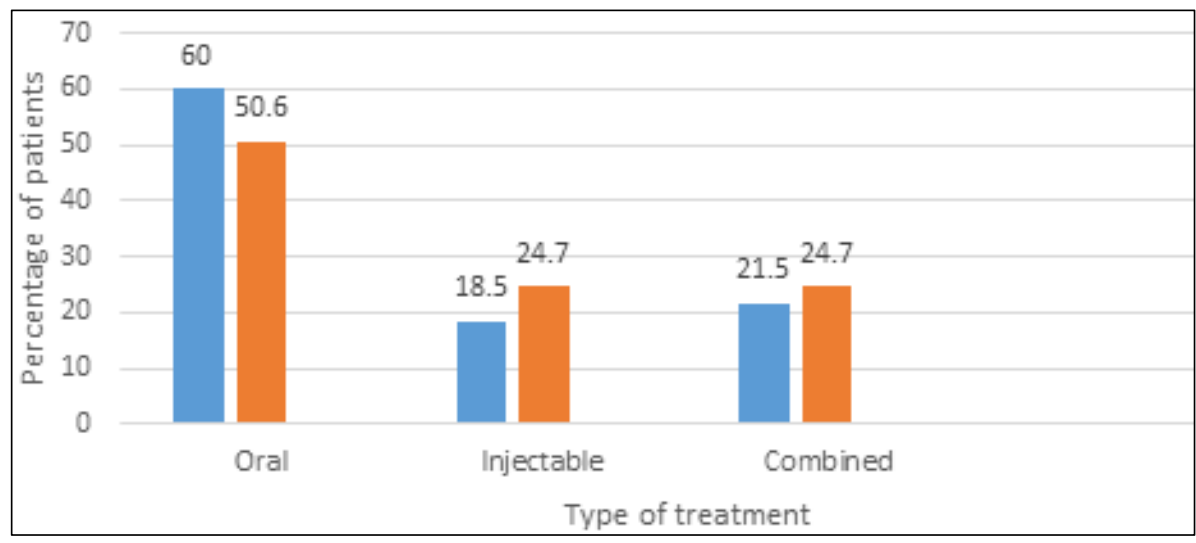

Figure 5. Distribution of the Type of Treatment According to the Sex.

Table 2 show the types of anti-diabetic therapy were used by the patients studied and their relation to the glycemic control. The majority $(53 \%)$ of the patients were prescribed oral antidiabetic drugs. Metformin (biguanide) only was the most common individual oral anti-diabetic drugs to be prescribed $22 \%$, followed by a combination of Metformin and sulfonylurea $19 \%$, followed by combination of metformin and dipeptidyl peptidase 4 inhibitors (DDP-4 inhibitors) $8 \%$, and sulfonylurea alone was 4\% (as shown in figure 6).

Insulin preparations alone accounted for $23 \%$ of the total anti-diabetic drugs and the most common preparation was premixed insulin (novomix) 10\% (as shown in figure 7).
Combined oral and injectable anti-diabetic drugs were $24 \%$, and the metformin (biguanide) and premixed preparation of insulin were the most common combined treatment were used (as shown in figure 8).

Of the 100 type 2 diabetic patients who were receiving anti-diabetic drugs, $10(10 \%)$ had controlled optimal glycemic control levels and mainly the patients who were receiving oral anti-diabetic drugs $5(5 \%)$, while $25(25 \%)$ had inadequately controlled glycemic levels (HbA1c between 78.9). 65 (65\%) patients had poor glycemic control (HbA1c $\geq$ 9) and mainly those patients on oral anti-diabetic drugs as shown in figure 9.

Table 2. Interrelationship of Diabetic Treatment Subtypes with Glycemic Control by HbAlc.

\begin{tabular}{|c|c|c|c|c|c|c|c|}
\hline Type of treatment & $\begin{array}{l}\text { Good control } \\
(<7) . \text { No. of } \\
\text { patient }\end{array}$ & $\%$ & $\begin{array}{l}\text { Inadeq-uate } \\
\text { control }(7-8.9) \\
\text { No. of patients }\end{array}$ & $\%$ & $\begin{array}{l}\text { Poor control } \\
(\geq 9) \text { No. of } \\
\text { patients }\end{array}$ & $\%$ & $\begin{array}{l}\text { Total No. } \\
\text { of patients }\end{array}$ \\
\hline Oral & 5 & $5 \%$ & 15 & $15 \%$ & 33 & $33 \%$ & 53 \\
\hline *Biguanides (Metformin) & 2 & $2 \%$ & 5 & $5 \%$ & 15 & $15 \%$ & $22 \%$ \\
\hline *Sulphonylureas & 0 & $0 \%$ & 2 & $2 \%$ & 2 & $2 \%$ & $4 \%$ \\
\hline *Combination of biguanides and sulphonylureas & 2 & $2 \%$ & 6 & $6 \%$ & 11 & $11 \%$ & $19 \%$ \\
\hline *Combination of biguanide and DDP- 4 inhibitors & 1 & $1 \%$ & 2 & $2 \%$ & 5 & $5 \%$ & $8 \%$ \\
\hline
\end{tabular}




\begin{tabular}{|c|c|c|c|c|c|c|c|}
\hline Type of treatment & $\begin{array}{l}\text { Good control } \\
(<7) . \text { No. of } \\
\text { patient }\end{array}$ & $\%$ & $\begin{array}{l}\text { Inadeq-uate } \\
\text { control }(7-8.9) \\
\text { No. of patients }\end{array}$ & $\%$ & $\begin{array}{l}\text { Poor control } \\
(\geq 9) \text { No. of } \\
\text { patients }\end{array}$ & $\%$ & $\begin{array}{l}\text { Total No. } \\
\text { of patients }\end{array}$ \\
\hline Injectable & 3 & $3 \%$ & 6 & $6 \%$ & 14 & $14 \%$ & 23 \\
\hline *Soluble insulin and long acting insulin & 1 & $1 \%$ & 2 & $2 \%$ & 2 & $2 \%$ & $5 \%$ \\
\hline *Premixed (Novomix) & 1 & $1 \%$ & 1 & $1 \%$ & 8 & $8 \%$ & $10 \%$ \\
\hline$*_{\text {mixtard }}$ & 1 & $1 \%$ & 3 & $3 \%$ & 4 & $4 \%$ & $8 \%$ \\
\hline Combined treatment & 2 & $2 \%$ & 4 & $4 \%$ & 18 & $18 \%$ & 24 \\
\hline *Biguanides+insulin (mixtard) & 1 & $1 \%$ & 2 & $2 \%$ & 6 & $6 \%$ & $9 \%$ \\
\hline *Biguanides+sulphonylureas+insulin(mixtard) & 0 & $0 \%$ & 2 & $2 \%$ & 3 & $3 \%$ & $5 \%$ \\
\hline *Biguanide + Premixed (Novomix) & 1 & $1 \%$ & 0 & $0 \%$ & 9 & $9 \%$ & $10 \%$ \\
\hline Total $\%$ & $10 \%$ & & $25 \%$ & & $65 \%$ & & 100 \\
\hline
\end{tabular}

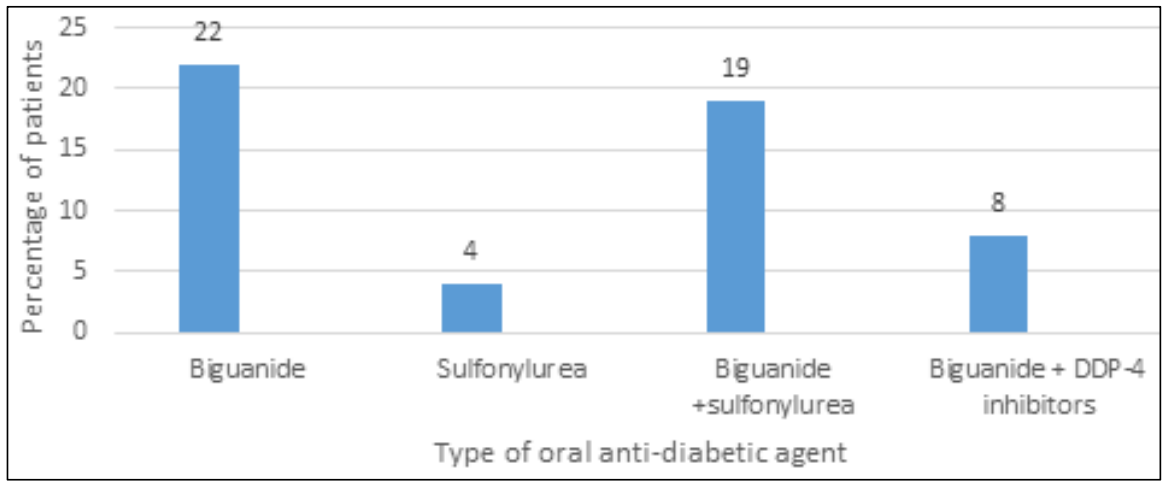

Figure 6. Distribution of the Diabetic Patients According to the Subtypes of Oral Anti-Diabetic Agents.

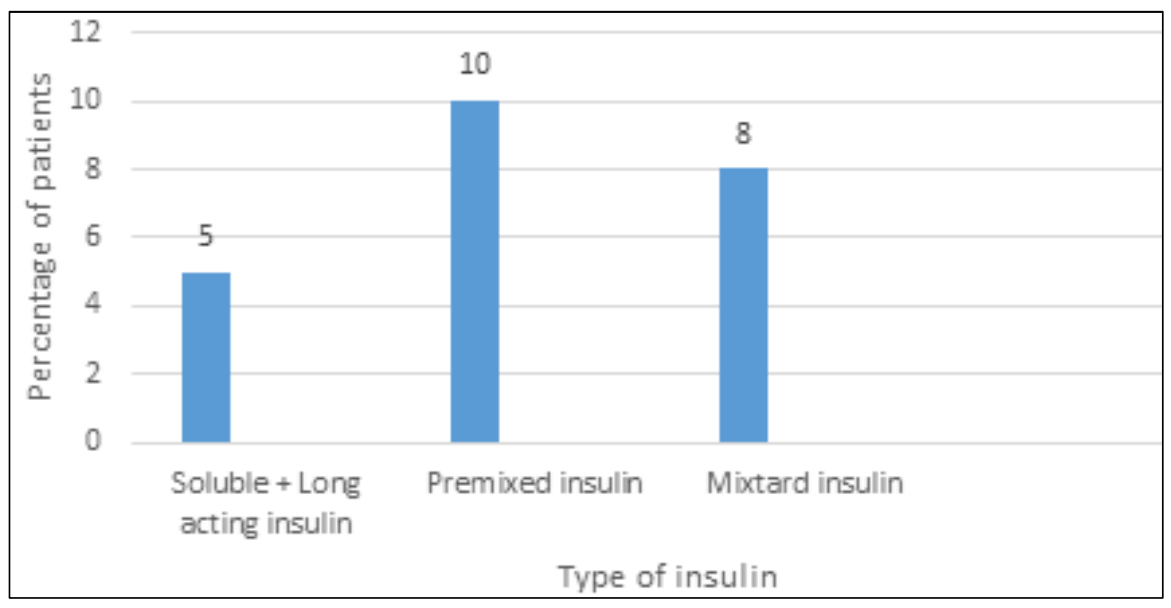

Figure 7. Distribution of the Diabetic Patients According to the Insulin Used.

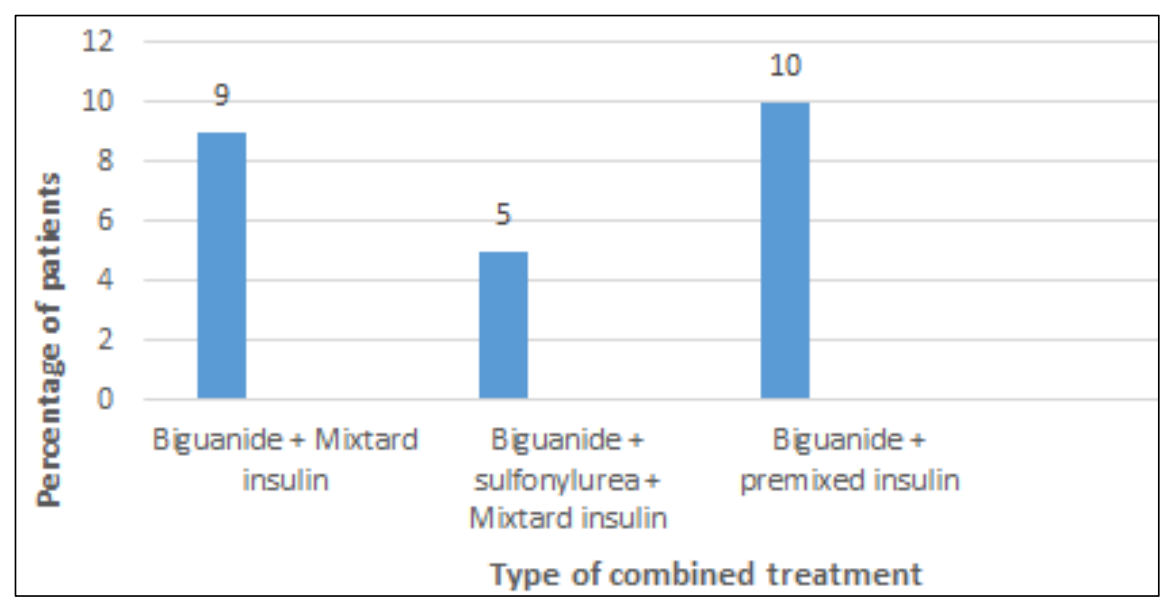

Figure 8. Distribution of the Diabetic Patients According to the Combined Treatment Used. 


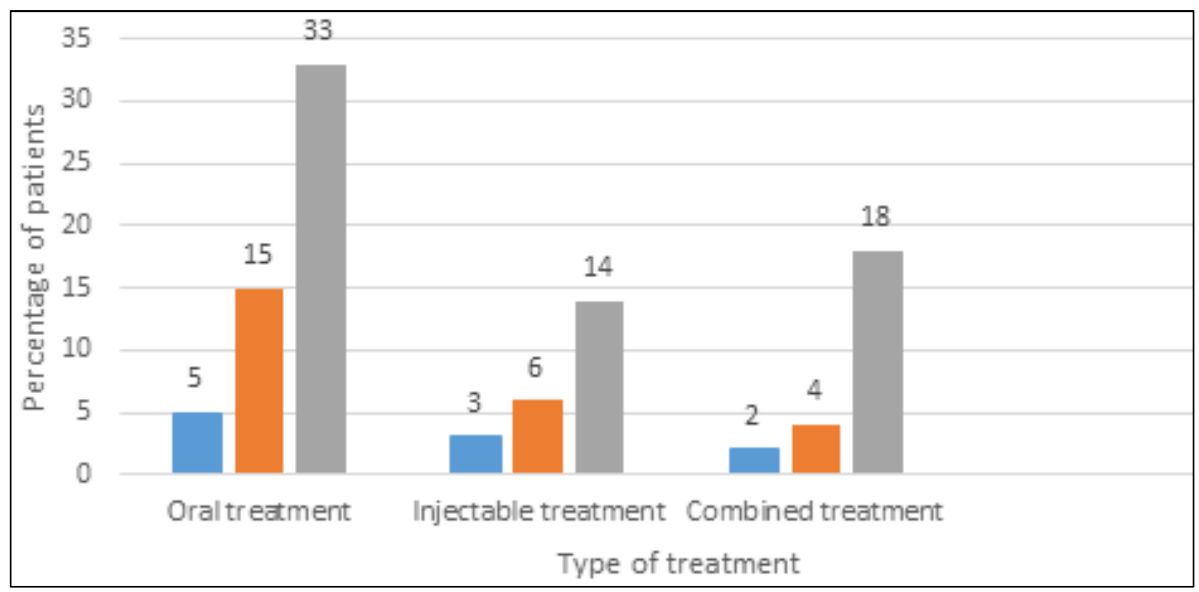

Figure 9. The Effect of Different Anti-Diabetic Agents on Glycemic Control by HbAlc.

\section{Discussion}

Out of 100 patients evaluated in this study, 27(27\%) were males and $73(73 \%)$ were females. Females predominated in the study population which agree with the result of a study in Taiwan, which show that the females are the predominate sex [25].

Out of 100 patients evaluated in this study, 43(43\%) $\{13(48 \%)$ were males and $30(41 \%)$ were females $\}$ were found in 51-60 years of age group, this result was similar to a study of Roy V et al (1998) [26]. Greater prevalence in this age group may be due to change in life style, lack of physical exercise and stress [27].

The majority of males $11(40 \%)$ in our study with BMI $\geq$ $25 \mathrm{~kg} / \mathrm{m}^{2}$ (overweight) and 45(61.3\%) females with a BMI $\geq$ $30 \mathrm{~kg} / \mathrm{m}^{2}$ (obese), which in itself is a well-recognized significant risk factor for diabetes mellitus.

About $10 \%$ patients, $2(7.5 \%)$ were males and $8(11 \%)$ were females, on anti-diabetic drugs had controlled glycemic levels (HbAlc <7), while $25 \%$ patients, $12(44.5 \%)$ were males and $13(18 \%)$ were females, had inadequate glycemic control levels (HbA1c 7-8.9). Poor glycemic control levels $(\mathrm{HbA} 1 \mathrm{c} \geq 9)$ were in $65 \%$ patients, $13(48 \%)$ were males and $52(71 \%)$ were females. Several studies [28, 29, 30] have documented higher than our studies. In our study, oral antidiabetic drugs were the most commonly used drugs accounting for $53 \%$ patients, $16(60 \%)$ were males and $37(50.6 \%)$ were females, which was similar to another studies [31, 32, 33].

It was found that among 100 patients with type 2 diabetes mellitus, 22(22\%) were prescribed Metformin alone, which was similar with other studies [27, 28]. This prescription pattern is according to guidelines of American Diabetes Association. They recommend that metformin should be started along with lifestyle changes at the time of diagnosis [34].

In this study, it was found that oral combination therapy was a common prescription pattern, 19(19\%) patients, which was a common finding seen with study of V. Sivasankari et al., and Das P et al., (2011) which also suggest combination of biguanides and sulfonylurea was most frequently used combination and most effective one [35, 36]. Co-prescription of a biguanides and sulfonylurea is a common practice [27].

The study documented low prescribing frequency of newer oral anti-diabetic drugs (DDP-4 inhibitors). They were used in combination with other oral anti-diabetic drugs mainly biguanides to achieve better glycemic control which was similar to other studies [31, 37].

Insulin preparations alone accounted for $23 \%$ of the total anti-diabetic drugs and the most common preparation was novomix insulin $10(10 \%)$. Our study showed a higher percentage of insulin use compared with other studies [32, 38].

The present study shows that $24 \%$ received insulin in combination with oral anti-diabetic drugs, which are similar to other study [38].

\section{Conclusion}

Oral anti-diabetic drugs were the most common prescribing drugs. Metformin was the commonest prescribing anti-diabetic drugs. Metformin and sulfonylurea being the most frequent combination prescribed. There were increasing in the use on insulin preparations in the treatment of type 2 diabetic patients. In achieving optimal glycemic control, the efficacy of anti-diabetic drugs was only $10 \%$, planning of more intensification anti-diabetic treatment is necessary.

\section{References}

[1] kyle Jeffrey starostka, pharm D candidates, a general overview of oral hypoglycemic for type 2 diabetes; Wyoming drug utilization review, 2008.

[2] Lawton C. Diabetes and aging: a growing concern. Perspectives 1994; 18(1):7-9.

[3] Ahmed, A. M. (2002) History of Diabetes Mellitus. Saudi Medical Journal, 23, 373-378.

[4] Olokoba, A. B., Obateru, O. A. and Olokoba, L. B. (2012) Type 2 Diabetes Mellitus: A Review of Current Trends. Oman Medical Journal, 27, 269-273. 
[5] Stratton, I. M., Adler, A. I., Neil, H. A., Matthews, D. R., Manley, S. E., Cull, C. A., Hadden, D., Turner, R. C. and Holman, R. R. (2000) Association of Glycemia with Macrovascular Complication of Type 2 Diabetes (UKPDS 35): Prospective Observational Study. British Medical Journal, 321, 405-412.

[6] Raz, I., Wilson, P. W., Strojerk, K., Kowalska, I., Bozikov, V., Gitt, A. k., Jermendy, G., Campaigne, B. N., Kerr, L., Milicevic, Z., et al. (2009) Effects of Prandial versus Fasting Glycemia on Cardiovascular Outcomes in Type 2 Diabetes: The Heart 2D Trial. Diabetes Care, 32, 381-386.

[7] Davis, S. N. and Granner, D. K. (2001) Insulin, Oral hypoglycemic Agents and Pharmacology Endocrine Pancreas. In: Hardman, J. G. and Limbird, L. E., Eds., Goodman and Gilman's T Pharmacological Basis of Therapeutics, McGraw Hill, New York, 1526-1531.

[8] Campbell, I. W. and Lebovitz, H. (2000) Fast Facts-Diabetes Mellitus; What Is Type 2 Diabetes? $2^{\text {nd }}$ Edition, Health Press Ltd., Oxford, 18-25.

[9] Cox, E. M. and Eleman, D. (2009) Test for screening and Diagnosis of Type 2 Diabetes. Clinical Diabetes, 4, 132-138.

[10] International Expert Committee (2009) International Expert Committee Report on the Role of AIC Assay in the Diagnosis of Diabetes. Diabetes Care, 32, 1-8.

[11] Hermansen K, Mortensen LS, Hermansen ML. Combining insulins with oral antidiabetic agents: Effect on hyperglycemic control, markers of cardiovascular risk and disease. Vasc Health Risk Manag. 2008;4:561-74.

[12] Sivaasankari V, Manivannan E, Priyadarsini SP. Drug utilization pattern of anti-diabetic drugs in a rural area of Tamilnadu, South India - A prospective, observational study. Int J Pharm Biol Sci. 2013;4:514-9.

[13] Gama H. Drug utilization studies. Arq Med. 2008;22:69-74.

[14] Davis SN. Insulin, oral hypoglycemic agents, and pharmacology of the endocrine pancreas. In: Brunton LL, Lazo JS, Parker KL, editors. Goodman and Gilman's The Pharmacological Basis of Therapeutics. $11^{\text {th }}$ ed. United States of America McGraw-Hill; 2006. pp. 1613-45.

[15] Powers AC. Diabetes mellitus. In: Kasper DL, Braunwald E, Fauci AS, Hauser SL, Lango DL, Jameson JL, editors. Harrison's Principles of Internal Medicine. $16^{\text {th }}$ ed. New York: McGraw-Hill; 2005. pp. 2152-80.

[16] Intensive blood-glucose control with sulfonylureas or insulin compared with conventional treatment and risk of complications in patients with type 2 diabetes (UKPDS 33). UK prospective Diabetes Study (UKPDS) Group. Lancet. 1998; 352: 837-53.

[17] Nathan, D. M., Buse, J. B., Davidson, M. B., Ferrannini, E., Holman, R. R., Sherwin, R., Zinman, B., American Diabetes Association and European Association for Study of Diabetes (2006) Management of Hyperglycemia in Type 2 Diabetes: A Consensus Algorithm for the Initiation and Adjustment of Therapy: A consensus statements from the American Diabetes Association and the European Association for the Study of Diabetes. Diabetes Care, 29, 1963-1972.

[18] Misra B, Jain SK, Mehta Y. A study on availability and prices of medicines in India. National Pharmaceutical Pricing Authority. 2002. \{Last accessed on 2013 Jul 20\}.
[19] Nagpal J, Bhartia A. Quality of Diabetes care in the middleand high-income group populace: The Delhi Diabetes Community survey. Diabetes Care. 2006;29:2341-8.

[20] Turner, R. C., Cull, C. A., Frighi, V. and Holman, R. R. (1999) Glycemic Control with Diet, Sulfonylurea, Metformin, or Insulin in Patients with Type 2 Diabetes Mellitus: Progressive Requirement for Multiple Therapies (UKPDS 49): UK Prospective Diabetes Study (UKPDS ) Group. Journal of American Nedical Association, 281, 2005-2012.

[21] Ohkubo Y, Kishihata H, Araki E, et al. Intensive insulin therapy prevents the progression of diabetic microvascular complication in Japanese patients with non-insulin-dependent diabetes mellitus: a randomized prospective 6-year study. Diabetes Res Clin Pract. 1995; 28:103-117.

[22] UK Prospective Diabetes Study (UKPDS) Group. Intensive blood-glucose control with sulfonylurea or insulin compared with conventional treatment and risk of complications in patients wiyh type 2 diabetes (UKPDS33). Lancet 1998; 352:837-853.

[23] Akila L, et al. Drug utilization study of oral antidiabetic drugs at a tertiary care hospital in Chennai. Int. J. Med. 2011; 1 (3):177-82.

[24] Dinesh KU, Subish P, Pranaya M. Pattern of potential drugdrug interactions in diabetic out-patients in a Tertiary Care Teaching Hospital in Nepal. Medical Journal of Malaysia. 2007;62(4):294-8.

[25] Tseng CH. The Epidemiological Transition of Diabetes Mellitus in Taiwan: Implication for Reversal of Female Preponderance from a National Cohort. The Open Diabetes Journal. 2009;2:18-23.

[26] Roy V, Rewaris S. Ambiguous drug pricing: A physician's dilemma. Indian J Pharmacol. 1998;30:404-7.

[27] Vengurlekar S, Patidar P, Bafna R, Jain S. Prescribing pattern of antidiabetic drugs in indore city hospital. Indian J Pharm Sci. 2008;70(5):637-40.

[28] Patel B, Oza B, Patel KP, Malhotra SD, Patel VJ. Pattern of antidiabetic drugs use in type-2 diabetic patients in a medicine outpatient clinic of a tertiary care teaching hospital. Int J Basic Clin Pharmacol. 2013;2:485-91.

[29] Willey CJ, Andrade SE, Cohen J, Fuller JC, Gurwitz JH. Polypharmacy with oral antidiabetic agents: An indicator of poor glycemic control. Am J Manag Care. 2006;12:435-40.

[30] Ben Abdelaziz A, Soltane I, Gaha K, Thabet H, Tlili H, Ghannem H. Predictive factors of glycemic control in patients with type 2 diabetes mellitus in primary health care. Rev Epidemiol Sante Publique. 2006;54:443-52.

[31] Hasamnis A, Patil S. Prescription pattern study in type 2 diabetes mellitus in an Indian referral hospital. Internet $\mathrm{J}$ Pharmacol. 2009;7:1.

[32] Sutharson L, Hariharan RS, Vamsadhara C. Drug utilization study in diabetology outpatient setting of a tertiary hospital. Indian J Pharmacol. 2003;35:237-40.

[33] Truter I. An investigation into antidiabetic medication prescribing in South Africa. J Clin Pharm Ther. 1998;23:417-22.

[34] National Diabetes Fact Sheet. American Diabetes Association. Available from: http:/www.diabetes.org/main/info/facts. 
[35] Sivasankari V, Manivannan E, Priyadarsini SP. Drug utilization pattern of anti-diabetic drugs in a rural area of Tamilnadu, South India - Aprospective, observational study. Int J Pharm Biol Sci. 2013;4:514-9.

[36] Das P, Das BP, Rauniar GP, Roy RK, Sharma SK. Drug utilization pattern and effectiveness analysis in diabetes mellitus at a tertiary care centre in Eastern Nepal. Indian J Physiol Pharmacol. 2011;55:272-80.
[37] Sultana G, Kapur P, Aqil M, Alam MS, Pillai KK. Drug utilization of oral hypoglycemic agents in a university teaching hospital in india. J Clin Pharm Ther. 2010;35:267-77.

[38] Rajeshwari S, Adikhari P, Pai MR. Drug utilization study in geriatric type 2 diabetic patients. J Clin Diagn Res. 2007;1:440-3. 